
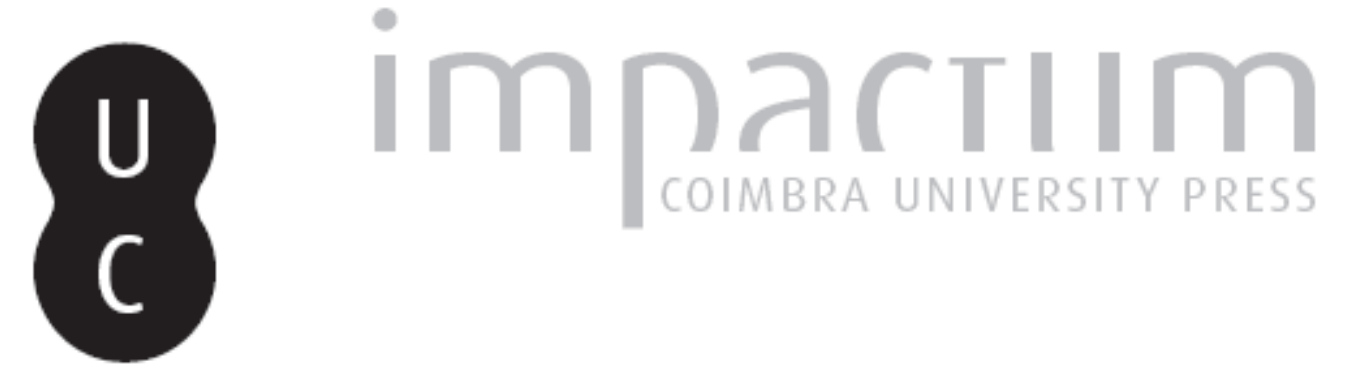

\title{
[Recensão a] Jacques Derrida entre France et Allemagne, Les Cahiers Philosophiques de Strasbourg, no 39/2016, Christian Ferrié e Jacob Rogozinski (ed.)
}

\author{
Autor(es): $\quad$ Mendes, André; Carvalho, Andreia; Padilha, Bruno; Amaral, Hugo
}

Publicado por: Imprensa da Universidade de Coimbra, Instituto de Estudos Filosóficos

URL persistente:

URI:http://hdl.handle.net/10316.2/42154

DOI:

DOI:http://dx.doi.org/10.14195/0872-0851_51_9

Accessed : $\quad$ 26-Apr-2023 09:43:13

A navegação consulta e descarregamento dos títulos inseridos nas Bibliotecas Digitais UC Digitalis, UC Pombalina e UC Impactum, pressupõem a aceitação plena e sem reservas dos Termos e Condições de Uso destas Bibliotecas Digitais, disponíveis em https://digitalis.uc.pt/pt-pt/termos.

Conforme exposto nos referidos Termos e Condições de Uso, o descarregamento de títulos de acesso restrito requer uma licença válida de autorização devendo o utilizador aceder ao(s) documento(s) a partir de um endereço de IP da instituição detentora da supramencionada licença.

Ao utilizador é apenas permitido o descarregamento para uso pessoal, pelo que o emprego do(s) título(s) descarregado(s) para outro fim, designadamente comercial, carece de autorização do respetivo autor ou editor da obra.

Na medida em que todas as obras da UC Digitalis se encontram protegidas pelo Código do Direito de Autor e Direitos Conexos e demais legislação aplicável, toda a cópia, parcial ou total, deste documento, nos casos em que é legalmente admitida, deverá conter ou fazer-se acompanhar por este aviso.






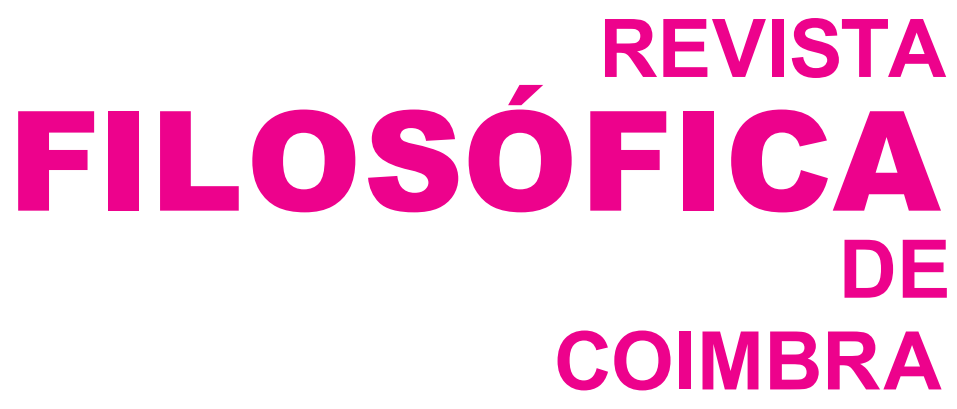

vol. 26 - número 51 - março 2017

vol. 26 - número 51 - março 2017

Fundação Eng. António de Almeida

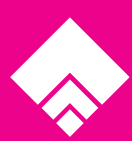


Jacques Derrida entre France et Allemagne, Les Cahiers Philosophiques de Strasbourg, no 39/2016, Christian Ferrié e Jacob Rogozinski (ed.), Strasbourg: Presses Universitaires de Strasbourg, 2016, 224 páginas.

O mais recente número dos Cahiers Philosophiques de Strasbourg reúne as conferências proferidas no âmbito do Colóquio Internacional Jacques Derrida entre France et Allemagne. Lectures Allemandes de Derrida. Organizado por Christian Ferrié e Jacob Rogozinski, este colóquio, que teve lugar na Universidade de Strasbourg e no Théâtre National de Strasbourg de 1 a 2 de Dezembro de 2014, e que contou com a ilustre presença e a participação de Jean-Luc Nancy e de Werner Hamacher, pretendeu homenagear e comemorar o pensamento de Jacques Derrida, dez anos volvidos sobre a sua morte.

Não sem sublinhar a importância de o evento ter decorrido em Strasbourg, lugar que esteve sempre associado, para Derrida, à experiência da amizade de pensamento e da hospitalidade, a introdução de Christian Ferrié e Jacob Rogozinski enuncia o propósito: por um lado, tratava-se de seguir Derrida na sua condição de autor lido na Alemanha, por outro, de dar a pensar Derrida como leitor de autores de língua alemã. É lembrado que Derrida nunca silenciou o seu interesse filosófico por autores de língua alemã (de Kant a Hegel, passando, entre outros, por Nietzsche, Benjamin, Husserl, Kafka, Celan e Silesius, sem esquecer Schmitt e, obviamente, Heidegger). Aliás, sem nunca ter deixado de sublinhar a relação única, de «admiração contrariada», com Heidegger, Derrida foi, com Levinas, dos primeiros a salientar a gravidade do alcance e das consequências políticas da obra do filósofo alemão, saudando-lhe a grandeza e demarcando-se dela ao mesmo tempo.

No seu texto - intitulado «Justice, amitié, bonheur. Derrida et l'éthique kantienne» (p. 25-41) -, David Espinet advoga existir, a partir dos anos 80, uma certa «viragem kantiana» no pensamento de Jacques Derrida - embora a ideia de «viragem», «kantiana», «ética», «política» ou outra, nos pareça fortemente problemática à luz do idioma de pensamento derridiano: convém, aliás, lembrar que o próprio filósofo se demarcou reiteradamente desta ideia. No entanto, para D. Espinet, o pensamento do filósofo francês ter-se-ia então tornado «mais comprometido». É este tom de crescente comprometimento que D. Espinet procura aqui perscrutar através do tríptico justiça-amizade-felicidade. Ora, se a justiça e a amizade encontram larga expressão no léxico derridiano, o mesmo não se passa, 
pelo menos aparentemente, com a felicidade. Socorrendo-se da última entrevista do filósofo, David Espinet pretende mostrar como a questão da felicidade não está nunca separada da questão da justiça e da amizade. Através de uma leitura da filosofia prática de Kant, o autor assinala a síntese impossível que se joga entre justiça, amizade e felicidade. Entre atracção (fusão, apropriação do outro) e repulsa (distância, respeito pela alteridade do outro), que nunca se adequam completamente uma à outra. Esta permanente inadequação abre espaço para pensar a justiça, já não como ideia reguladora, mas antes como ideia desreguladora da ordem jurídica, política, etc. A síntese entre atracção e distância está sempre por inventar, por negociar. A cada momento.

Gérard Bensussan - em «De la circoncision comme philosophème» (p. 43-57) - investiga as diferentes operações que o quase-conceito de «circuncisão» leva a cabo no pensamento filosófico moderno e contemporâneo, e aqui mais precisamente em Hegel e em Derrida. No pensamento de Derrida, a «circuncisão» designa a singularidade da relação do filósofo ao judaísmo mas ela é também, e sobretudo, o nome da relação a um evento que «se recorda a mim sem ter tido lugar». Ela é, assim, o índice de um passado imemorial, que dá a pensar a ex-apropriação originária do sujeito e a sua suposta identidade a si, e, por conseguinte, a «circuncisão» é o índice de um resto absoluto que jamais se deixa re-absorver ou capturar pelo movimento dialéctico. Separação absoluta. Mas é precisamente, segundo Bensussan, por significar «separação» que a «circuncisão» ocupa também um importante lugar no pensamento de Hegel. E se Derrida se esforça por "su-portar" o segredo da «circuncisão», Hegel procede antes a uma espécie de «des-circuncisão». Neste contexto, o cristianismo aparece como a cura: ele é chamado a suprir a negação, a separação que a «circuncisão» inscreve na própria pele. Cristo como a negação da negação. Teríamos assim dois modos da «circuncisão» como «conceito» filosófico: negação ao serviço da dialéctica ou différance.

Jérôme Lèbre, por sua vez, aproxima a relação entre Hegel e Derrida em termos de uma singular «correspondência» que, hipótese do autor, daria a pensar um incessante «desvio» deste último por Berlim antes de regressar a França. «Détours d'une correspondance franco-allemande: entre Hegel et Derrida» (p. 59-76) segue assim uma «circulação» de cartas habitadas pela (in)segurança da sua própria destinação, cujo principal destaque vem a ser dado à leitura de Derrida da correspondência entre Victor Cousin e Hegel, a fim de evidenciar que, se por um lado encontramos uma certa «presença espectral» de Hegel a operar em todo o corpus derridiano, por outro lado, esta efectivou-se sempre, por parte do pensamento da Desconstrução, como afirmação da diferença irredutível (différance) que ininterruptamente interrompe o movimento de releva da dialéctica hegeliana (Aufhebung).

Fogo que queima ou fogo como ordem mortal de abrir fogo, Jacob Rogozinski - em «Feu la mort: deuil, survie, résurrection» (p. 77-90) - inscreve o 
pensamento da morte segundo duas concepções: ou a antecipação da morte, o aprender e o exercitar-se a morrer; ou a vitória sobre a morte, a morte da morte. Finitude assumida ou Aufhebung. Pergunta o autor: de que lado está Derrida? Segundo Jacob Rogozinski, a leitura de Blanchot permite a Derrida escapar a esta dolorosa alternativa. Sobrevida, a vida/a morte, dá a pensar a «contaminação indecidível da vida e da morte», ou uma «morte sem morte da morte». Mas o autor crê ler em Derrida ainda uma certa vacilação entre a sobrevida como uma vida hiperbólica e uma melancolia assombrada pela (não-)experiência da morte. Rogozinski evoca então o poeta Antonin Artaud, que nos daria talvez a pensar uma outra sobrevivência. Uma outra experiência de sobrevida. Mas: poderá uma afirmação da vida não ser assombrada pela morte?

É ainda com uma recensão de uma obra da autoria de Jacob Rogozinski (Cryptes de Derrida. Paris: Nouvelles éditions Lignes, 2014) que encerra este volume dos Cahiers Philosophiques de Strasbourg.

«De la Destruktion à la Déconstruction: de la mort et de la peine de mort» (p. 91-109), de Fernanda Bernardo, espelha a preocupação com a detecção da singularidade da Desconstrução derridiana como idioma filosófico, não só relativamente a Heidegger, mas, mais latamente, ao todo da tradição filosófica - no contexto específico deste Colóquio, a autora perscruta esta singularidade através da «Auseinandersetzung» que terá sempre sido o modo da relação de Derrida com o pensamento e a obra de Heidegger, sem todavia apagar a assumida dívida do «pensamento da escrita» às questões heideggerianas. Na memória de que Strasbourg foi o palco, quer da primeira cidade-refúgio, quer da última experiência parlamentar de Jacques Derrida que, a convite de Emma Bonino e do Tribunal Europeu dos Direitos do Homem, ali proferiu o seu incondicional «requisitório contra a pena de morte», a autora salienta esta «Auseinandersetzung» entre Derrida e Heidegger através da problemática da morte (sendo Heidegger o filósofo do sein-zum-Tode) e da pena de morte: a indeterminação do tempo da morte, que expõe a fragilidade ou a ficcionalidade da soberania (subjectiva e Estatal) e revela ainda o «humanismo» ou o «antropocentrismo» da propriedade da morte atribuída por Heidegger exclusivamente ao Dasein, é o fio perseguido para aqui salientar o desvio entre Déconstruction e Destruktion e para apelar a pensar o mecanismo jurídico da pena de morte, a soberania, a autoridade e a violência, estatais ou não, nos nossos tempos de mundialização.

Zeynep Direk desenvolve sob o título «Derrida entre Hegel et Lacan: la subjectivité aporétique» (p. 111-127) alguns dos traços de proximidade e de distância que caracterizam a relação do pensamento derridiano da aporia ao idealismo hegeliano e à psicanálise lacaniana. Através de um detalhado percurso em torno da constituição da «subjectividade» por relação à noção de "desejo", a autora desenvolve a noção de uma "subjectividade aporética" a partir da aporia pensada como experiência ou resistência interminável e não dialectizável, bem como a partir do «alargamento» da noção de outro pensado para-além do vivente 
humano. Não obstante, o texto apresenta-se ainda, em vários momentos, numa linha notoriamente lacaniana, permitindo-nos o seu terminus perscrutar o alcance inerente à aproximação da relação ao outro em termos de uma experiência aporética do impossível, nomeadamente no que concerne a questão da animalidade e a questão da dita "diferença sexual", que Derrida pensou sempre no plural.

«Entre Husserl et Freud, Derrida. La temporalité husserlienne et ce qu'il en reste...» (p. 129-142), de Élise Lamy-Rested, traz-nos um ensaio que tudo deve à escuta de um pensamento da alteridade radical, irredutível e irrepresentável, que desloca e desconstrói a temporalidade da presença que, de Platão a Husserl, fundou a filosofia e a história do ocidente. Com Derrida, Élise Lamy-Rested põe a análise fenomenológica fora de si mesma, contestando-a a partir das descrições do movimento da temporalização, levantando questões como: de que modo é que a teoria husserliana, que pretende desordenar a definição clássica de tempo inaugurada por Aristóteles, continua refém da ideia da temporalidade da consciência? De que modo é que a temporalidade do presente vivo não se distingue, no limite, da temporalidade da Nachträglichkeit freudiana? Ou em que medida é que um pensamento da sobre-vida se revela a «fonte» para repensar a fenomenologia como metafísica da presença na forma da idealidade ou do privilégio da palavra viva (phoné)?

«Interprétation et Différence. Derrida, lecteur de Nietzsche et de Heidegger» (p. 143-163) é o título do texto de Philipp Schwab no qual é desenvolvida uma linha de aproximação possível da relação do pensamento derridiano ao pensamento heideggeriano. Sendo inquestionável que Derrida marca o seu distanciamento para com o pensamento de Heidegger em toda a sua obra, não deixando contudo de reconhecer a importância inegável da abertura das questões heideggerianas, a hipótese do autor é a de que as diferenças a operar na leitura efectivada por ambos os filósofos do «gesto nietzschiano», nomeadamente a «suspeita» dirigida ao movimento pelo qual Heidegger tenta reunir o pensamento de Nietzsche numa "unidade", constituiria o lugar particularmente relevante onde um tal distanciamento se evidencia, vindo ainda a formar um contributo decisivo para a exposição do "conceito" de différance como (não-)nome da diferença irredutível.

Em «La passion noire ou le rêve d'une amitié inusable dans Politiques de l'amitié de Derrida» (p. 165-173), Leonard Lawlor expõe parte do seu projecto em torno do «pior» com o intuito de estudar possibilidades de resposta ao «pior como violência» (p. 165). Para isso, mostrará a atenção de Derrida à Gelassenheit (Heidegger), aí identificando a noção de «respeito» (p. 165) conduzido a um conceito de amizade imperecível, inscrita em Politiques de l'amitié. Lawlor parte assim da inversão (Nietzsche) do célebre enunciado atribuído a Aristóteles: «"Amigos, não há de todo amigos!" exclamava o sábio moribundo / "Inimigos, não há de todo inimigo!" exclama o louco vivente que eu sou» (p.165).

Ao longo do ensaio, o autor salienta o ardil do sábio moribundo - interpelando os amigos -, que se disfarça de louco vivente - interpelando os inimigos -, 
dissimulando o amor que pretende manter em segredo. Inversão e dissimulação que se reflectirão num conjunto de aparentes paradoxos - proximidade no afastamento, amizade na inimizade, igualdade na desigualdade, etc. -, colocando em cena uma «paixão negra» ou uma «amizade imperecível», uma «generosidade» (p. 166) incondicional, da entrega incondicional ao outro - do qual nada se espera em troca -, cujo respeito pela sua irredutibilidade envolve o afastamento, tendente a um respirar (despossessão) imperecível, avesso à apropriação (possessão) asfixiante do outro - «amor hiperbólico» (p. 170).

O ensaio de Christian Ferrié - «La politique de Derrida contre l'hostilité schmittienne» (p. 175-195) - pretende dar conta da leitura que, em Politiques de l'amitié, Derrida faz do pensamento de Carl Schmitt sobre a hostilidade. Pensando «um mundo sem amigo, sem inimigo» (Derrida) (p. 175), Ferrié procurará mostrar que se, por um lado, Schmitt preconiza uma clara delimitação do inimigo; por outro, Derrida desconstrói tal delimitação apontando já uma «perda do sentido do inimigo» (p. 175). Confrontando o pensamento de Derrida e Schmitt, Ferrié sublinhará a abissalidade que os separa, quer a nível de conteúdo - Derrida é o filósofo da «política da hospitalidade absoluta» e Schmitt o jurista-filósofo da «polemologia da hostilidade absoluta» (p. 175) - quer a nível da forma - a Desconstrução de Derrida envolve uma «deslocação absoluta», colocando em causa a axiomática em que Schmitt pretende apoiar-se. No presente texto, Ferrié tenta acompanhar a subtileza e a finura da análise de Derrida ao pensamento de Schmitt, permitindo-lhe aproximar a Desconstrução deste e, no mesmo gesto, não raro, a denúncia das incongruências ou mesmo da «hipocrisia» (p. 182) que o filósofo francês logra desvelar por entre a sinuosa e «espectral» (p. 181) arquitectura argumentativa do jurista-filósofo alemão.

André Mendes / Andreia Carvalho / Bruno Padilha / Hugo Amaral 
(Página deixada propositadamente em branco.) 